\title{
THE RELATIVISTIC HEAVY ION COLLIDER (RHIC) REFRIGERATOR SYSTEM AT BROOKHAVEN NATIONAL LABORATORY: PHASE III OF THE SYSTEM PERFORMANCE AND OPERATIONS UPGRADES FOR 2006
}

\author{
A. Sidi-Yekhlef ${ }^{1}$, R. Than ${ }^{1}$, J. Tuozzolo ${ }^{1}$, V. Ganni ${ }^{2}$, P. Knudsen ${ }^{2}$, \\ D. Arenius ${ }^{2}$ \\ ${ }^{1}$ Brookhaven National Laboratory \\ Upton, NY, 11973, USA \\ ${ }^{2}$ Thomas Jefferson National Accelerator Facility \\ Newport News, VA, 23606, USA
}

\begin{abstract}
An ongoing program at Brookhaven National Laboratory (BNL) consists of improving the efficiency of the Relativistic Heavy Ion Collider (RHIC) cryogenic system and reducing its power consumption. Phase I and II of the program addressed plant operational improvements and modifications that resulted in substantial operational cost reduction and improved system reliability and stability, and a compressor input power reduction of $2 \mathrm{MW}$ has been demonstrated. Phase III, now under way, consists of plans for further increasing the efficiency of the plant by adding a load "wet" turbo-expander and its associated heat exchangers at the low temperature end of the plant. This additional stage of cooling at the coldest level will further reduce the required compressor flow and therefore compressor power input. This paper presents the results of the plant characterization, as it is operating presently, as well as the results of the plant simulations of the various planned upgrades for the plant. The immediate upgrade includes the changes associated with the load expander. The subsequent upgrade will involve the resizing of expander 5 and 6 to increase their efficiencies. The paper summarizes the expected improvement in the plant efficiency and the overall reduction in the compressor power.
\end{abstract}

KEYWORDS: helium, plant, refrigerator, liquefier, efficiency

PACS: 01.30.Cc, 89.20.Kk 


\section{INTRODUCTION}

The basic function and operating features of the RHIC cryogenic system have been described in other publications ${ }^{1,2}$. Originally designed for ISABELLE, it is essentially a Claude cycle with helium as a working fluid, using oil-bearing turbine-expanders and warm oil-flooded screw compressors, with no liquid nitrogen pre-cooling assistance.

This ISABELLE refrigerator was adapted to meet present RHIC refrigeration requirements, i.e. about $8 \mathrm{~kW}$ of $4.5 \mathrm{~K}$ refrigeration, $50 \mathrm{~g} / \mathrm{s}$ of liquefaction and a $25 \mathrm{~kW} 50 \mathrm{~K}$ (nominal) shield. The ISABELLE refrigerator was designed for a much larger load than the present RHIC load by a factor greater than three. The present plant is operating at approximately half the Carnot efficiency, and approximately half the flow of the ISABELLE design. It has two streams (a high and low pressure stream) and uses six expanders. Operation of the expanders and heat exchangers substantially below their design flows contribute to the lower operating efficiency of the plant. The colder heat exchangers and expanders are the largest contribution to the low efficiency. The Phase III modification consists of adding an additional expansion step using a load "wet" turbineexpander (T7) and additional heat exchangers at the low temperature end (or load end) of the plant. The integration of these modifications will further reduce the required compressor flow and discharge pressure, resulting in further reduction in input power. Figure 1 shows a schematic of the RHIC refrigerator upgraded with the load expander system and a liquid nitrogen pre-cooler (although it should be noted that the pre-cooler is not part of the Phase III upgrade).

\section{PLANT CYCLE MODELS}

In order to predict the power consumption of the upgraded plant, and size the new load turbine-expander and additional heat exchangers, the new operating conditions of the upgraded plant had to be determined. To accomplish this, plant process cycle models were developed for the existing plant and the upgraded plant. The existing plant's overall

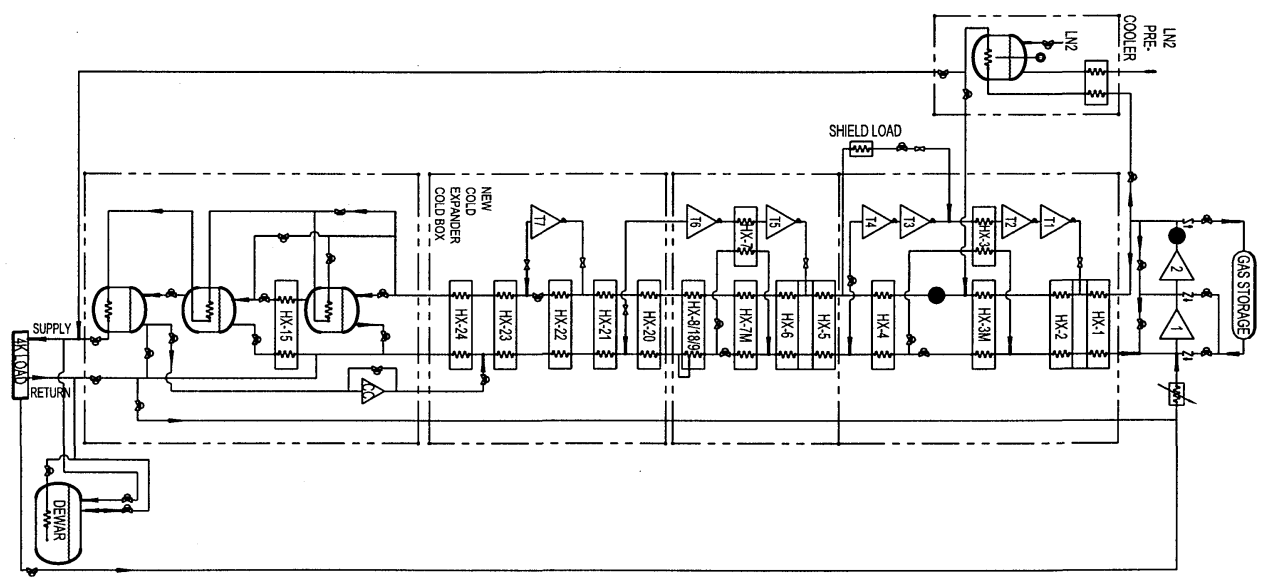

FIGURE 1. Process Flow Diagram for Upgraded RHIC Plant. 
performance and its components performance were characterized with the plant cycle model using operating data. The new operating conditions could then be determined using the component characterizations in the modified process cycle.

Excel spreadsheet models were developed using mass and energy balance equations. These models utilize custom Visual Basic code for modeling the compressors, expanders and heat exchangers and interface with Cryodata's HePak helium properties library. In these models the load conditions, control volume temperatures, expander inlet or outlet temperature, complete pressure conditions, and component characterization correlations are entered (as known parameters). Historical performance characteristics of these components from other plants were also used in the plant model to cross check the performance of this plant's components. These models not only serve to evaluate the plant's over-all performance, as well as the component performance, but they are also used to cross check predicted operating conditions against actual plant operating data (i.e. instrumentation accuracy against model accuracy). It should be stressed that careful examination between model results and plant operating data are required so that discrepancies can be identified as model (or characterization) and/or instrumentation error.

After discrepancies have been resolved and historical performance has been crosschecked, these plant simulations were used to provide the predicted operating conditions, new component process requirements, power consumption and overall efficiency of the modified cycle.

\section{EVALUATION OF PLANT OPERATING DATA}

Using the plant operating data collected during the last two years for the current operating conditions and data collected this year at reduced compressor flow, the performance of all major components in the system (i.e. compressors, heat exchangers, expanders, etc.) has been evaluated over the operating range of the plant in order to characterize the following:

1. Compressor efficiencies (volumetric and isothermal).

2. Expander efficiencies vs. volumetric flow-rate.

3. Heat exchangers overall heat transfer coefficient times total surface area (UA)'s vs. mass flow-rate.

Because the plant will be operating more efficiently after the upgrade, the flow through the expanders and heat exchangers will be lower than the current plant conditions. To obtain data at lower flows for the component characterizations, the plant was "turneddown" while handling the collider's loads. This was accomplished by using liquid helium inventory from the large sub-cooler vessels during the turndown and/or by reducing the collider power leads cooling equivalent make-up flow (sent to warm storage).

Typical results of the component characterization are plotted in the following figures for each of the major components in the system. 

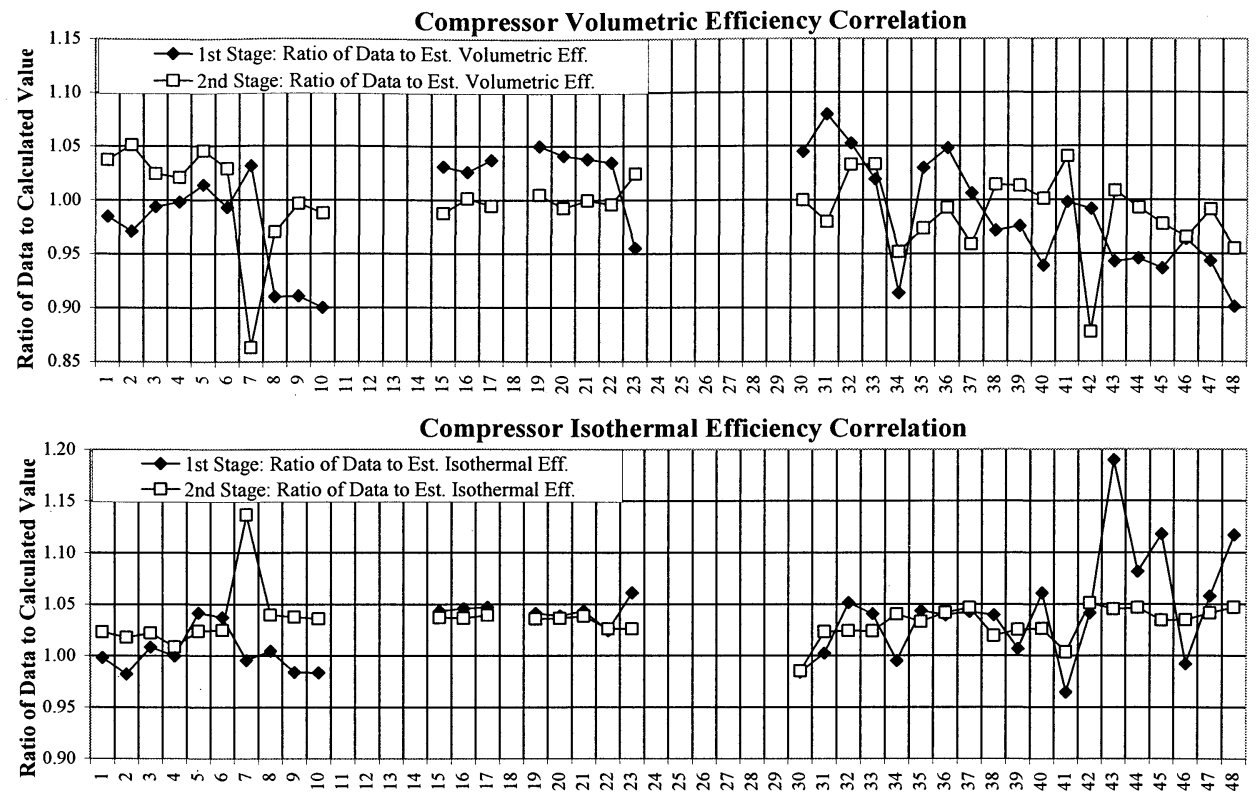

FIGURE 2. Compressor Characterization: Isothermal and Volumetric Efficiencies.

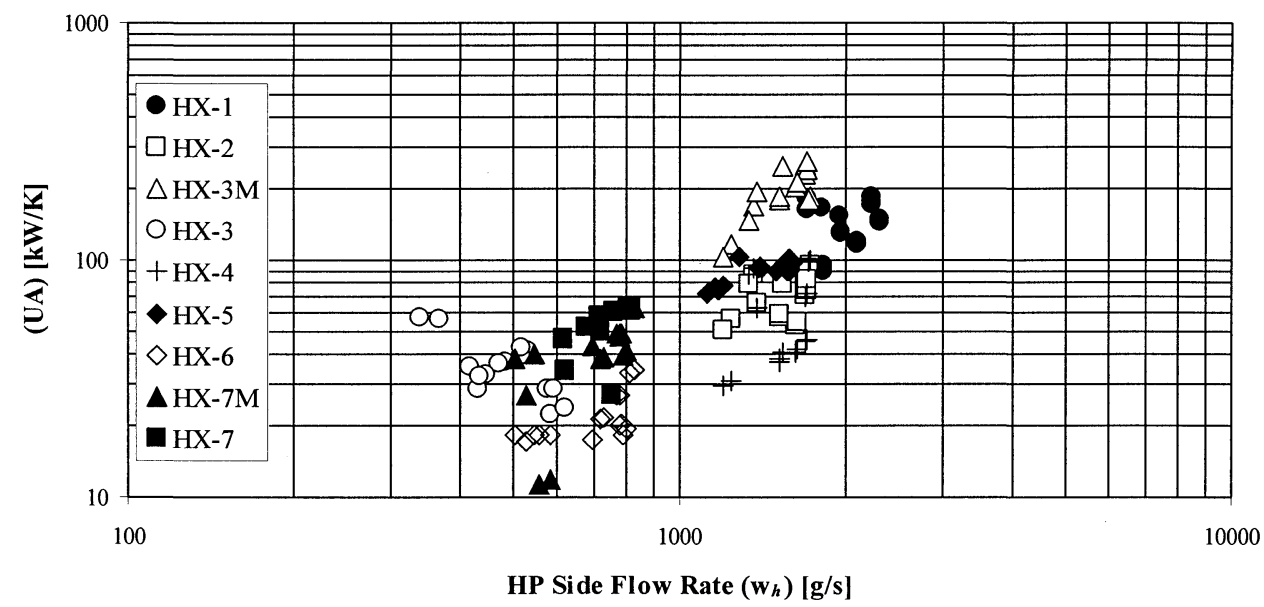

FIGURE 3. Heat Exchanger Characterization: (UA)'s. 

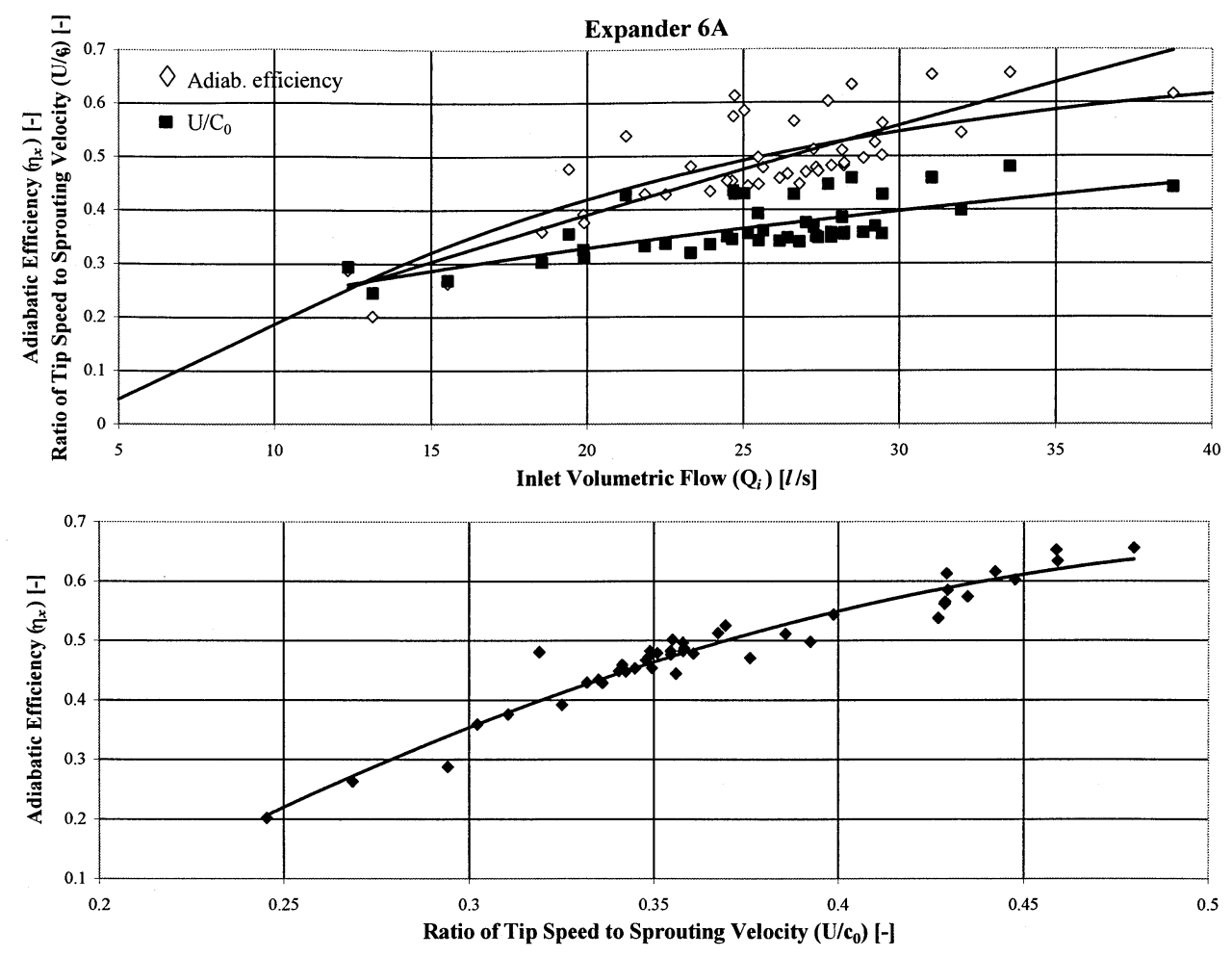

FIGURE 4. Expander Characterization: Adiabatic Efficiency.

Simulation of the existing plant model with operating data showed that the instrumentation accuracy is quite good. However, the primary mass flow-meter (F1) of the plant, which measures the total flow from the compressor system to the cold-box, did not match the predicted flow, while other instrumentation and component performance indicated that the model prediction was correct. This Venturi flowmeter (F1) was found to be to indicate a reading approximately $14 \%$ lower than the computer model predicted. After careful evaluation of the flow meter, plant data and model predictions it was found that the vendor originally used the wrong discharge coefficient sizing the Venturi. The discharge coefficient has been corrected and now the sum total of the plant's other flow meters matches the corrected F1 main flow to within 2 percent.

Compressor performance matches close to historical data for similar size SRM screw compressors (to within 2 percent). First stage compressors are operating at 56 to 58 percent isothermal efficiency and a (approximately) 90 percent volumetric efficiency. Second stage compressors are operating at 56 to 58 percent isothermal efficiency and an (approximately) 88 percent volumetric efficiency. The warm expander train (T1 to T4) is operating closer to design efficiency (approximately 75 percent string adiabatic efficiency), but the cold expander train (T5 and T6) is operating at less than design efficiency (approximately 48 percent). All the heat exchangers are operating substantially less efficient because of flow mal-distribution problems attributed to a horizontal flow path design and operating at approximately half the original design flow. The degradation predictably is more severe in the low temperature heat exchangers since the density effects are more predominant. 
The performance of the existing heat exchangers is expected to degrade further with the implementation of the system upgrade because of the (expected) further flow reduction. To address this problem, as part of the upgrade additional heat exchangers will be added to the low-temperature end of the cold box.

\section{CYCLE ANALYSIS SUMMARY}

\section{Current Plant Evaluation}

TABLE 1 indicates the existing loads for the plant and the total required Carnot work. TABLE 2 summarizes the RHIC's plant current performance. It represents three different compressor supply pressures. During steady state, the compressor discharge pressure typical varies between $1.4 \mathrm{MPa}$ to $1.45 \mathrm{MPa}$.

\section{Upgraded Plant Evaluation}

The upgraded plant consists of the addition of five new heat exchangers from approximately $15 \mathrm{~K}$ to the $4.5 \mathrm{~K}$ end of the plant and a new load expander operating nominally at an inlet temperature of $6.7 \mathrm{~K}$. The expander is expected to operate at an adiabatic efficiency of between 72 to 75 percent. The expander outlet pressure of $0.43 \mathrm{MPa}$ is set by the operating pressure requirements of the Collider's magnet loop.

After having established the present plant performance model, plant models were developed with the load expander upgrade. In addition, plant simulations were carried out with the load expander not operating (shut-down) and (separately) with an upgrade of expanders 5 and 6 . TABLES 3 to 6 present the summary of these simulations. It should be noted that further plant simulations would be needed after the load expander upgrade to more accurately assess the efficiency improvement by upgrading expanders 5 and 6 .

TABLE 1. Loads.

\begin{tabular}{lrl}
\hline Shield $(40-55 \mathrm{~K})$ & 25 & {$[\mathrm{~kW}]$} \\
Refrigeration (4.5K) & 8200 & {$[\mathrm{~W}]$} \\
Liquefaction & 32 & {$[\mathrm{~g} / \mathrm{s}]$} \\
Total Load Carnot Work (Approx.) & 940 & {$[\mathrm{~kW}]$} \\
\hline
\end{tabular}

TABLE 2. Existing Plant Evaluation (Phase III baseline).

\begin{tabular}{lrrrl}
\hline \multicolumn{1}{c}{$\begin{array}{c}\text { Cold Box Supply Pressure } \\
\text { (Case) }\end{array}$} & \multicolumn{1}{c}{$\begin{array}{c}\mathbf{1 . 3 2} \\
\mathbf{( 1 )}\end{array}$} & \multicolumn{1}{c}{$\begin{array}{c}\text { (2) } \\
\text { (1.42 }\end{array}$} & \multicolumn{1}{c}{ (3) } & [MPa] \\
\hline Input Power & 7.44 & 7.10 & 7.17 & {$[\mathrm{MW}]$} \\
Carnot Efficiency & $12.6 \%$ & $13.3 \%$ & $13.2 \%$ & \\
Cold Box Supply Flow & 2397 & 2338 & 2308 & {$[\mathrm{~g} / \mathrm{s}]$} \\
$\# 1^{\text {st }}$ Stage Compressors & 11 & 10 & 10 & \\
$\# 2^{\text {nd }}$ Stage Compressors & 3 & 3 & 3 & \\
$1^{\text {st }}$ Stage Bypass & 327 & 136 & 165 & {$[\mathrm{~g} / \mathrm{s}]$} \\
Interstage Pressure & 0.373 & 0.364 & 0.360 & {$[\mathrm{MPa}]$} \\
\hline
\end{tabular}


TABLE 4. Upgraded Plant, new load expander not operational.

\begin{tabular}{lrrrl}
\hline $\begin{array}{c}\text { Cold Box Supply Pressure } \\
\text { (Case) }\end{array}$ & \multicolumn{1}{c}{$\begin{array}{c}\mathbf{1 . 3 2} \\
(\mathbf{1})\end{array}$} & \multicolumn{1}{c}{$\mathbf{1 . 3 7}$} & \multicolumn{1}{c}{$\mathbf{1 . 4 2}$} & {$[\mathrm{MPa})$} \\
\hline Input Power & 6.79 & 6.79 & 6.52 & {$[\mathrm{MW}]$} \\
Carnot Efficiency & $13.9 \%$ & $13.9 \%$ & $14.5 \%$ & {$[-]$} \\
Cold Box Supply Flow & 2201 & 2128 & 2086 & {$[\mathrm{~g} / \mathrm{s}]$} \\
$\# 1^{\text {st }}$ Stage Compressors & 10 & 10 & 9 & {$[-]$} \\
$\# 2^{\text {nd }}$ Stage Compressors & 3 & 3 & 3 & {$[-]$} \\
$1^{\text {st }}$ Stage Bypass & 269 & 342 & 132 & {$[\mathrm{~g} / \mathrm{s}]$} \\
Interstage Pressure & 0.343 & 0.332 & 0.325 & {$[\mathrm{MPa}]$} \\
\hline
\end{tabular}

TABLE 5. Upgraded Plant, new load expander.

\begin{tabular}{lcrrl}
$\begin{array}{c}\text { Cold Box Supply Pressure } \\
\text { (Case) }\end{array}$ & $\begin{array}{c}\mathbf{1 . 3 2} \\
(\mathbf{1})\end{array}$ & $\begin{array}{c}\mathbf{1 . 3 7} \\
(\mathbf{2})\end{array}$ & $\begin{array}{c}\mathbf{1 . 4 2} \\
\mathbf{( 3 )}\end{array}$ & {$[\mathrm{MPa}]$} \\
\hline Input Power & 5.55 & 5.64 & 5.73 & {$[\mathrm{MW}]$} \\
Carnot Efficiency & $16.9 \%$ & $16.7 \%$ & $16.4 \%$ & {$[-]$} \\
Cold Box Supply Flow & 1768 & 1743 & 1713 & {$[\mathrm{~g} / \mathrm{s}]$} \\
$\# 1^{\text {st }}$ Stage Compressors & 8 & 8 & 8 & {$[-]$} \\
$\# 2^{\text {nd }}$ Stage Compressors & 3 & 3 & 3 & {$[-]$} \\
$1^{\text {st }}$ Stage Bypass & 189 & 215 & 245 & {$[\mathrm{~g} / \mathrm{s}]$} \\
Interstage Pressure & 0.277 & 0.274 & 0.269 & {$[\mathrm{MPa}]$} \\
\hline
\end{tabular}

TABLE 6. Upgraded Plant, incorporating upgrade of expanders 5 and 6.

\begin{tabular}{|c|c|c|c|c|}
\hline $\begin{array}{c}\text { Cold Box Supply Pressure } \\
\text { (Case) }\end{array}$ & $\begin{array}{c}1.32 \\
(1)\end{array}$ & $\begin{array}{c}1.37 \\
(2)\end{array}$ & $\begin{array}{c}1.42 \\
(3)\end{array}$ & {$[\mathrm{MPa}]$} \\
\hline Input Power & 4.75 & 4.75 & 4.77 & {$[\mathrm{MW}]$} \\
\hline Carnot Efficiency & $19.7 \%$ & $19.6 \%$ & $19.6 \%$ & {$[-]$} \\
\hline Cold Box Supply Flow & 1533 & 1485 & 1448 & {$[\mathrm{~g} / \mathrm{s}]$} \\
\hline$\# 1^{\text {st }}$ Stage Compressors & 7 & 7 & 7 & {$[-]$} \\
\hline$\# 2^{\text {nd }}$ Stage Compressors & 2 & 2 & 2 & {$[-]$} \\
\hline $1^{\text {st }}$ Stage Bypass & 175 & 222 & 260 & {$[\mathrm{~g} / \mathrm{s}]$} \\
\hline Interstage Pressure & 0.362 & 0.351 & 0.342 & {$[\mathrm{MPa}]$} \\
\hline
\end{tabular}

\section{CONCLUSIONS}

Phase III of the RHIC cryogenic system upgrade is in the process of being implemented. The current plant has been characterized using the operating data for the purpose of establishing the new operating conditions for the upgraded plant. The process cycle models predict a system Carnot efficiency improvement from the current $13 \%$ to approximately $16.5 \%$ with the addition of the load expander and the new heat exchangers. A Carnot efficiency of approximately $19.5 \%$ appears to be possible with further upgrades of expanders 5 and 6 . These efficiency improvements will correspond to a power consumption reduction of $1.5 \mathrm{MW}$ with the new load expander and an additional $0.8 \mathrm{MW}$ with upgraded cold end expanders (5\&6). 


\section{ACKNOWLEDGEMENTS}

Work performed under the auspices of the U.S. Department of Energy Contract No. DE-AC02-98CH10886, BNL-73416-2004-CP

\section{REFERENCES}

1. Brown, D.P. et al., "Cycle Design for the ISABELLE Helium Refrigerator," Advances in Cryogenic Engineering 27, edited by R.W. Fast, Plenum Press, New York, 1981, pp. 501-516.

2. Brown, D.P. et al., "Operational Tests of the BNL $24.8 \mathrm{~kW}, 3.8 \mathrm{~K}$ Helium Refrigerator", Advances in Cryogenic Engineering 31, edited by R.W. Fast, Plenum Press, New York, 1986, pp. 627-633. 